\title{
Studies of industrial emissions by accelerator-based techniques: A review of applications at CEDAD
}

\author{
L. Calcagnile* and G. Quarta \\ CEDAD-Department of Innovation Engineering, University of Salento \\ via per Monteroni, 73100, Lecce, Italy
}

\begin{abstract}
Different research activities are in progress at the Centre for Dating and Diagnostics (CEDAD), University of Salento, in the field of environmental monitoring by exploiting the potentialities given by the different experimental beam lines implemented on the 3 MV Tandetron accelerator and dedicated to AMS (Accelerator Mass Spectrometry) radiocarbon dating and IBA (Ion Beam Analysis). An overview of these activities is presented by showing how accelerator-based analytical techniques can be a powerful tool for monitoring the anthropogenic carbon dioxide emissions from industrial sources and for the assessment of the biogenic content in SRF (Solid Recovered Fuel) burned in WTE (Waste to Energy) plants.
\end{abstract}

\section{Introduction}

The CEDAD (Centre for Dating and Diagnostics) at the University of Salento, was established in 2001 to be a national centre for research and service in AMS (Accelerator Mass Spectrometry) radiocarbon dating [1]. In the first ten years of activity, CEDAD has fully respected its initial funding mission and is now a well established centre for AMS ${ }^{14} \mathrm{C}$ dating with more than $\sim 1000$ samples which are measured each year for applications spanning

${ }^{*}$ E-mail: lucio.calcagnile@unisalento.it

This is an Open Access article distributed under the terms of the Creative Commons Attribution License 2.0, which permits unrestricted use, distribution, and reproduction in any medium, provided the original work is properly cited. 
from Archaeological to Earth and Environmental Sciences. The research activities in the first decade of operation of the facility have been devoted to the application of the ${ }^{14} \mathrm{C}$ method to solve different archaeological problems, to the development of new, independent methods for the assessment of the preservation status of the submitted samples and of the accuracy of the data [2] as well as to the enhancement of the experimental potentialities by the design and installation of new beam lines.

Nowadays, beside the AMS ${ }^{14} \mathrm{C}$ dating spectrometer, four more beam lines are operational for RBS (Rutherford Backscattering Spectrometry), external beam PIXE (Particle Induced X-Ray)-PIGE (Particle Induced Gamma Ray), high energy ion implantation and Nuclear Microprobe [3]. Furthermore another multiisotope beam line, designed in collaboration with the AMS group at ETH in Zurich, is currently under installation for the detection of rare isotopes from ${ }^{10} \mathrm{Be}$ up to ${ }^{129} \mathrm{I}$ and actinides and it is expected to further extend the activities of CEDAD in the field of Earth and Ocean Sciences, Environmental Monitoring and Nuclear Safeguards. Together with these relevant technical and instrumental developments, the potentialities of AMS- ${ }^{14} \mathrm{C}$ dating and IBA techniques have been explored in areas different from the traditional ones related to cultural heritage diagnostics such as Earth and Life Sciences [4], Forensics [5] and environmental monitoring [6].

In this paper the basic aspects related to the potentialities of AMS in environmental monitoring are presented by reviewing recent applications for the study of the release of carbon dioxide from industrial sources and for the quantification of the biogenic fraction in the fuel used in WTE (Waste to Energy) plants in Italy.

\section{Experimental set-up}

A general layout of the AMS-IBA facility at CEDAD is shown in fig. 1. The system is based on a $3 \mathrm{MV}$ Tandetron accelerator manufactured by High Voltage Engineering Europa and equipped with two low energy injectors and five high energy experimental beam lines for AMS radiocarbon dating, RBS-Channeling, external beam PIXE-PIGE analyses, high energy ion implantation and IBA analyses at high spatial resolution by mean of a nuclear microprobe.

\subsection{Ion sources and injectors}

Two different low energy injectors are used for the production of ion beams to be injected in the accelerator: a multipurpose injector and a sequential 


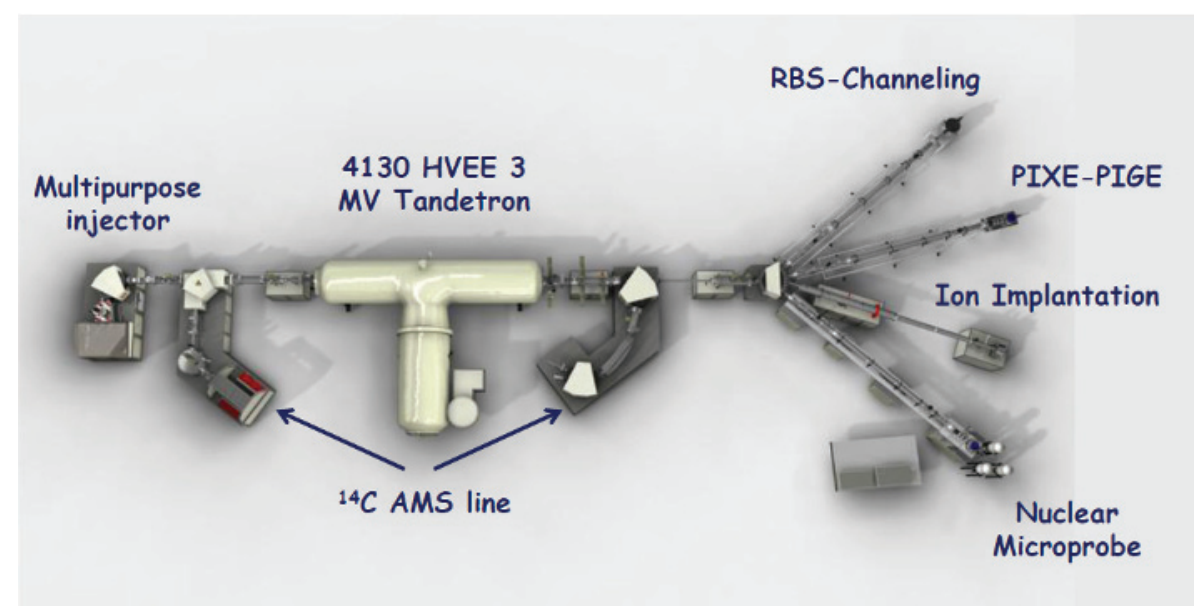

Figure 1: General layout of the facility installed at CEDAD.

injector dedicated to AMS. The multipurpose injector is equipped with two ion sources (a single cathode sputtering ion source and a Duoplamastron ion source) and a $90^{\circ}$ injection magnet. In routine operation the Duoplasmatron source is used for the production of alfa particles beams for application in RBS while the sputtering ion source is used for the extraction of negative ion beams from solid targets for ion implantation applications. The sputtering source is also routinely used for the extraction of proton beams by sputtering of $\mathrm{TiH}$ cathodes for external beam IBA analyses and in nuclear microprobe. The sequential injector is dedicated to AMS and, although for the moment it is used for the extraction and injection of negative carbon beams from graphite cathodes, it has been already modified to allow the injection of ions with masses up to Uranium, in the frame of the installation of the new multiisotope beam line. Although the detailed features of the AMS injector are reported elsewhere [7], it is essentially formed by a multicathode sputtering ion source (HVEE mod. 846A) with an automatic sample loading and unloading system and two dispersive elements: a $54^{\circ}$ ESA (Electrostatic Analyser) and a $90^{\circ}$ injection magnet.

\subsection{High energy AMS}

The high energy side of the facility includes the AMS high energy spectrometer and a high energy switching magnet which is used to bend the different ion beams in the other experimental lines. The AMS spectrometer is formed 
by three dispersive elements: a $110^{\circ}$ double focussing magnet which deflects the ${ }^{12} \mathrm{C}$ and ${ }^{13} \mathrm{C}$ stable carbon isotopes in two Faraday cups, a $33^{\circ}$ cylindrical ESA and a $90^{\circ}$ magnet which are both used to clean the ${ }^{14} \mathrm{C}$ beam from interfering particles and to deflect it into the final detector which consists of an isobutane, dual anodes gas ionization chamber. In terms of performances the AMS beam line, routine uncertainties of the order of $0.3-0.4 \%$ are reached in the ${ }^{14} \mathrm{C} /{ }^{12} \mathrm{C}$ ratio measurements while machine backgrounds far in the range of $10^{-16}$ have been demonstrated by measuring ${ }^{14} \mathrm{C}$-free unprocessed graphite samples [8].

\section{The contribution of ${ }^{14} \mathrm{C}-\mathrm{AMS}$ to environmental monitoring}

Radiocarbon is the radioactive isotope of carbon which is naturally produced in the upper atmosphere because of the nuclear interaction of cosmic rays with atmospheric nitrogen. Once produced, it is oxidized to carbon dioxide $\left({ }^{14} \mathrm{CO}_{2}\right)$ entering together with the two stable forms ${ }^{12} \mathrm{CO}_{2}$ and ${ }^{13} \mathrm{CO}_{2}$ into the different terrestrial reservoirs such as the atmosphere, the hydrosphere and the biosphere through the photosynthesis and the alimentary chain. As the results of these processes, all the living organisms reach a steady state equilibrium such as the ${ }^{14} \mathrm{C}$ concentration in their tissues reflects the actual value in the corresponding carbon reservoirs, which for the atmosphere is of the order of $10^{-12}$ in terms of ${ }^{14} \mathrm{C} /{ }^{12} \mathrm{C}$ ratio. The principle on which the radiocarbon dating method is based is that when the organisms dies no exchanges with the environment occur anymore and the ${ }^{14} \mathrm{C}$ concentration decreases following the radioactive decay law with an half life of 5730 years. Thus the measurement of the residual ${ }^{14} \mathrm{C}$ concentration in a sample allows to estimate the time elapsed since its death. It is worth noting that the actual application of this method is made more complex by several effects which have to be taken into account and for which the dates have to be corrected such as the isotopic fractionation occurring during the biological activity and the fluctuations of the atmospheric radiocarbon concentration over the time.

In fact although the original application of the radiocarbon method and of AMS was essentially in archaeological sciences for dating purposes, it has also given fundamental contribution in different branches of environmental sciences [9] such as atmospheric chemistry [10,11], in the study of the dynamics of atmospheric and ocean circulation [12] and in ice cores and climatic change research 
Another branch of applications of radiocarbon in environmental monitoring is that related to the use of radiocarbon as a tracer of the human impact on the environment. In fact different human activities can lead to relevant changes of the atmospheric radiocarbon concentration. The combustion of fossil fuels, for industrial purposes and energy production, results in the release into the atmosphere of large quantities of $\mathrm{CO}_{2}$ which, being completely depleted in their ${ }^{14} \mathrm{C}$ content, has a characteristic isotopic signature which can be effectively used to trace these emissions and their magnitude on a local as well as on a global scale. These deviations from the natural ${ }^{14} \mathrm{C}$ abundance can be in fact determined either by directly sampling atmospheric carbon dioxide or by analyzing biological materials recording it such as plants, tree leaves and tree rings.

More recently following the introduction of regulation promoting the use of bio-based carbon products and of renewable energy sources, new analytical methods based on AMS and radiocarbon have been developed for the assessment of the biogenic fraction in carbon based products (polymers, resins and plastic products) and in the waste-derived fuels used in WTE plants $[13,14]$.

\section{Applications}

We review two applications carried out at CEDAD in the field of environmental monitoring for the study of the $\mathrm{CO}_{2}$ released from industrial sources in Southern Italy and for the determination of the biogenic fraction in fuels used in WTE plants in Northern Italy.

\subsection{Studying the release of ${ }^{14} \mathrm{C}$-depleted $\mathrm{CO}_{2}$ by AMS}

As it has been pointed out before the release of ${ }^{14} \mathrm{C}$-depleted carbon dioxide from industrial sources burning fossil fuels results in local depletion of the radiocarbon concentration (local dilution effect). This " 14 C-depleted" carbon dioxide is thus recorded, through photosynthesis, by the plants living in the surrounding environment which thus act as bio-indicators of the magnitude and the dispersion paths of the fossil emissions.

We selected different grass samples from the area surrounding the industrial area of Brindisi which is one of the most industrialized district in Southern Italy and which includes large factories (coal and oil fired power plants and chemical industries) which are expected to release significant quantities of carbon dioxide deriving from the combustion of fossil fuels. As indicators of the atmospheric ${ }^{14} \mathrm{C}$ levels, leafs of common grass plants were 


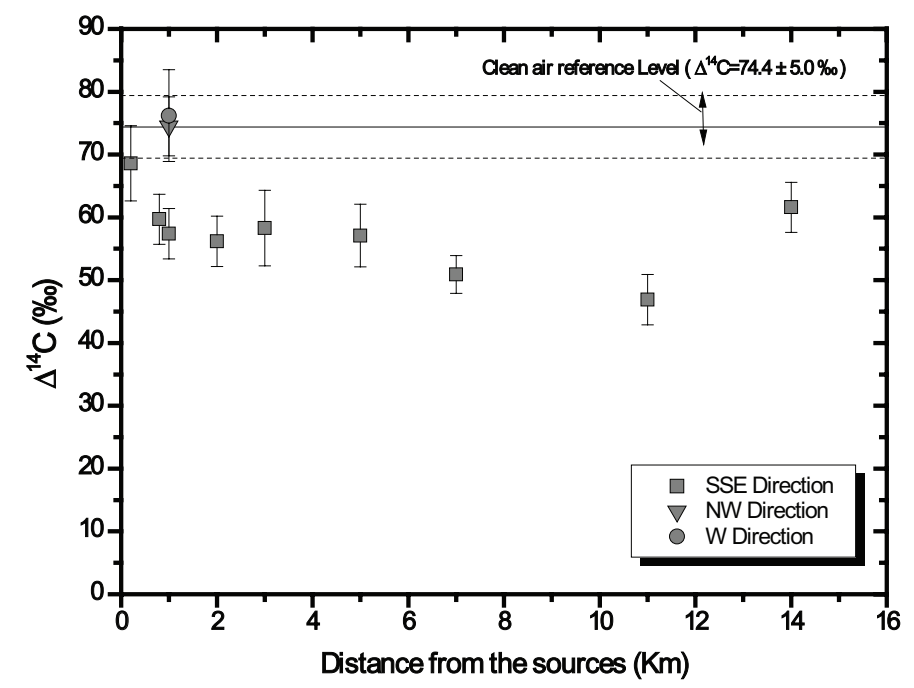

Figure 2: $\Delta{ }^{14} \mathrm{C}$ term as a function of the distance from the emission sources in the industrial district of Brindisi along different directions.

sampled during the spring-summer growing periods in 2004 and 2005. Different samples were taken at different distances and in different directions from the industrial area to study the dispersion mechanisms and the possible relationships with meteorological factors such as the direction of the prevalent winds. In order to have an estimation of the local "undisturbed" ${ }^{14} \mathrm{C}$ concentration samples were also taken in Castro, $90 \mathrm{Km}$ South from Brindisi where no industrial effects are expected.

The results of the measurements are given in fig. 2 and are expressed in terms of $\Delta^{14} \mathrm{C}$ values. The figures shows that while the samples taken in the $\mathrm{NW}$ and $\mathrm{W}$ direction show radiocarbon concentrations not distinguishable from the clean air reference value $\left(\Delta^{14} \mathrm{C}=74.4 \pm 5.0\right)$, the samples taken along the SSE direction exhibit depleted values, except for the first sample having a $\Delta^{14} \mathrm{C}$ value overlapping, within measurement uncertainty, with the undisturbed atmospheric levels. These measurements indicate a local depletion effect of the natural atmospheric ${ }^{14} \mathrm{C}$ concentration as resulted by the release of carbon dioxide of fossil origin from the industrial sources. Furthermore they demonstrate a preferential distribution of the released $\mathrm{CO}_{2}$ along the direction of the prevalent winds, blowing in this area from NNW and S. From a more quantitative point of view the obtained results can be also used to estimate the magnitude of the emission by calculating 
the term $C_{f}$ representing the molar fossil-fuel fraction and given by:

$$
C_{f}=\frac{\Delta^{14} C_{\text {clean }}-\Delta^{14} C_{\text {sample }}}{\Delta^{14} C_{\text {clean }}+1000} \cdot 100 \%,
$$

where $\Delta^{14} C_{\text {sample }}$ and $\Delta^{14} C_{\text {clean }}$ indicate the $\Delta^{14} \mathrm{C}$ value measured for the sample and for the clean-air reference, respectively. The results show a magnitude of the dilution effect ranging from $1.4 \%$ at $800 \mathrm{~m}$ from the industrial area to $2.6 \%$ at $11 \mathrm{~km}$.

\subsection{Determining the biogenic component in $\mathrm{CO}_{2}$ emitted from WTE plants}

Following the general concern related to global warming and to greenhouse gas emissions reduction different efforts are being made at the national and international level promoting the use of renewable resources for energy production. In the European Union the Directive 2009/28/EC dated 23 April 2009 includes biomass and the biodegradable fraction of industrial and municipal waste in the list of renewable energy sources. Following this definition only the fraction of energy produced by the combustion of the biogenic fraction of waste can be labeled as coming from renewable sources. This has led to research efforts for the development of proper, accurate methodologies for the determination of the proportion between fossil and biogenic carbon in the fuel used in WTE plants in order to assess the amount of energy which can be labeled as coming from renewable sources. In fact in this field radiocarbon AMS is gaining importance in the last years because of the significant advantages with respect to the traditional methods such as the manual sorting, the selective dissolution [15] and the energy balance method [16]. The radiocarbon based method is quite simple in its principle and it is based on the large ${ }^{14} \mathrm{C}$ isotopic difference between the fossil-derived (completely depleted ${ }^{14} \mathrm{C}$ ) and the biogenic component of the combusted waste, whose radiocarbon content reflects current ${ }^{14} \mathrm{C}$ atmospheric levels. Thus the estimation of the portions of biogenic and fossil fractions can be carried out by solving isotopic mass balance equations, after the measurement of the radiocarbon concentration in the carbon dioxide sampled directly at the stack of the WTE plants. We carried out in collaboration with RSE-Spa (Ricerche sul Sistema Energetico) a measurement campaign on emission samples taken at the stack of three energy plants in Northern Italy. The three plants were a $113 \mathrm{MW}$ turbogas cogeneration plant burning fossil methane (expected biocontent $0 \%$ ), 1.2 MW landfill biogas burner (expected bio-content 100\%) and a $9 \mathrm{MW}$ fluidized bed WTE plant burning SRF derived from municipal solid 


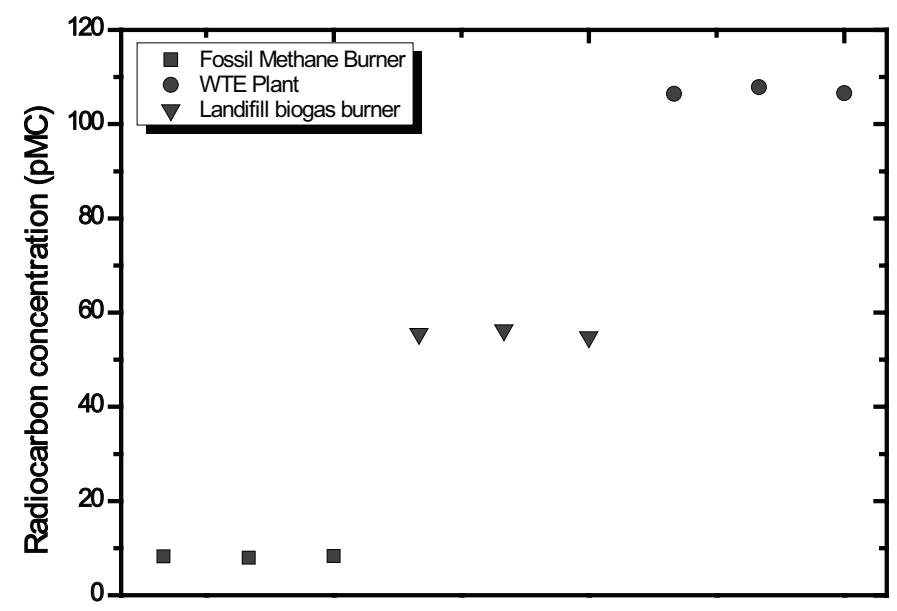

Figure 3: Measured radiocarbon concentrations for the three samples taken in three consecutive days from the three plants.

waste. Three samples were taken in three consecutive days from the plants. On site sampling was carried out by dissolving the $\mathrm{CO}_{2}$ in $4 \mathrm{M} \mathrm{KOH}$ solution by using the apparatus developed by RSE and $\mathrm{CO}_{2}$ was extracted by acidification with $\mathrm{H}_{3} \mathrm{PO}_{4}$ of $200 \mu \mathrm{l}$ of samples solution. The results of the measurements obtained for the three plants are reported in fig. 3 in terms of pMC (Percent Modern Carbon) values. These results allow to qualitatively distinguish between the three different plants according to the different level of radiocarbon measured in the three plants.

A four component isotopic mass balance model was then developed and used for the calculation of the biogenic content in the WTE plant in order to take into account the contribution given by the atmospheric air used during the combustion process and to properly correct the measurements for the ${ }^{14} \mathrm{C}$ background due to the sampling, storage and processing procedures [17]. The biogenic content $\left(x_{\text {bio }}\right)$ was thus calculated by the formula:

$$
x_{\text {bio }}=\frac{f_{\text {meas }}-x_{\text {atm }} f_{\text {atm }}-x_{\text {sol }} f_{\text {sol }}}{f_{\text {bio }}},
$$

where $f_{\text {meas }}$ is the measured ${ }^{14} \mathrm{C}$ content in the sample, $x_{\text {atm }}$ and $f_{\text {atm }}$ is the contribution from atmospheric air; $x_{\mathrm{sol}}$ and $f_{\text {sol }}$ is the contribution of the sampling solution; $f_{\text {bio }}$ is the ${ }^{14} \mathrm{C}$ concentration of the pure biogenic waste. By following this approach for the WTE plant the following biogenic fractions were calculated: $45.4 \pm 1.6 \%, 46.3 \pm 1.6 \%$ and $44.8 \pm 1.6 \%$ for the three consecutive days of sampling. These results are statistically consistent 
among them and allowing to calculate an average value, with the uncertainty given as scattering of the data, for the biogenic fraction of $45.5 \pm 0.8 \%$ as average for the plant during the three days. The comparison of the value measured by AMS and the vale determined alternatively by the dissolution method $(44.0 \pm 1.9 \%)$ show the consistency of the two data at the one sigma level.

\section{Conclusions}

Accelerator based analytical techniques, and in particular AMS and IBA, have a great potential in Environmental sciences and monitoring as shown by several studies and research projects. The general features of the accelerator based facility at CEDAD (Centre for Dating and Diagnostics) more relevant in this area of research have been review together with some applications carried out by using radiocarbon as an isotopic tracer for the monitoring of the anthropogenic emissions of carbon dioxide into the atmosphere from industrial sources and for the determinations of the biogenic content in fuel used in energy power plants burning waste.

\section{References}

[1] Calcagnile L, Quarta G, D'Elia M, Rizzo A, Gottdang A, Klein M, Mous DJW. A new accelerator mass spectrometry facility in Lecce, Italy. Nuclear Instruments and Methods in Physics Research, Section B: Beam Interactions with Materials and Atoms; 223-224 (SPEC. ISS.) (2004) 16.

[2] Quarta G, Butalag K, Calcagnile L, D'Elia M. Applications of accelerator-based analytical methods to archaeological sciences. Nuovo Cimento B; 122 (2007) 773.

[3] Quarta G, D'Elia M, Butalag K, Maruccio L, Demortier G, Calcagnile L. An integrated accelerator mass spectrometry radiocarbon dating and ion beam analysis approach for the study of archaeological contexts. Applied Physics A: Materials Science and Processing; 83 (2006) 605.

[4] Quarta G, D'Elia M, Calcagnile L, Belmonte G, Ingrosso G. Reconstructing the formation mechanism of submarine biogenic stalactites: The contribution of AMS. Nuclear Instruments and Methods in Physics Research, Section B: Beam Interactions with Materials and Atoms; 268 (2010) 1244. 
[5] Zavattaro D, Quarta G, D'Elia M, Calcagnile L. Recent documents dating: An approach using radiocarbon techniques. Forensic Sci Int; 167 (2007) 160.

[6] Quarta G, D'Elia M, Rizzo GA, Calcagnile L. Radiocarbon dilution effects induced by industrial settlements in southern Italy. Nuclear Instruments and Methods in Physics Research, Section B: Beam Interactions with Materials and Atoms; 240 (2005) 458.

[7] Calcagnile L, Quarta G, D'Elia M. High-resolution accelerator-based mass spectrometry: Precision, accuracy and background. Applied Radiation and Isotopes; 62 (2005) 623.

[8] Calcagnile L, Quarta G, D'Elia M, Gottdang A, Klein M, Mous DJW. Radiocarbon precision tests at the lecce AMS facility using a sequential injection system. Nuclear Instruments and Methods in Physics Research, Section B: Beam Interactions with Materials and Atoms; 215 (2004) 561.

[9] Kutschera W, AMS and Climate Change. Nuclear Instruments and Methods in Physics Research, Section B: Beam Interactions with Materials and Atoms; 268 (2010) 693.

[10] Levy H., Normal Atmosphere: Large Radical and Formaldehyde Concentrations Predicted. Science; 173 (1971) 141.

[11] Crutzen P.J., A discussion of the chemistry of some minor constituents in the stratosphere and troposphere. Pure Appl. Geophys.; 106-108 (1973) 1385.

[12] Key R.M., WOCE Pacific Ocean radiocarbon program. Radiocarbon; 38 (1996) 415.

[13] Hamalainen K.M., Jungner H., Antson O., Rasanen J., Tormonen K., Roine J., Measurement of biocarbon in flue gases using ${ }^{14} \mathrm{C}$. Radiocarbon; 49 (2007) 325.

[14] Mohn J, Szidat S, Fellner J, Rechberger H, Quartier R, Buchmann $\mathrm{B}$, Emmenegger L, Determination of biogenic and fossil $\mathrm{CO}_{2}$ emitted by waste incineration based on ${ }^{14} \mathrm{CO}_{2}$ and mass balances. Bioresource Technology; 99 (2008) 6471. 
[15] European Committee for Standardization CEN, TS15440 Solid Recovered Fuels-Method for the determination of biomass Content. Brussels (2006) 44.

[16] Fellner J, Cencic O, Recheberger H, New Method to Determine the Ratio of Electricity Production from Fossil and Biogenic Sources in Waste-to-Energy Plants. Environ. Sci. Technol.; 41 (2007) 2579.

[17] Calcagnile L, Quarta G, D'Elia M, Ciceri G, Martinotti W, Radiocarbon AMS determination of the biogenic component in $\mathrm{CO}_{2}$ emitted from waste incineration. Nuclear Instruments and Methods in Physics Research, Section B: Beam Interactions with Materials and Atoms (in press). 